\title{
Clinical, Genetic, and Biophysical Characterization of a Homozygous HERG Mutation Causing Severe Neonatal Long QT Syndrome
}

\author{
WALTER H. JOHNSON, JR, PING YANG, TAO YANG, YUNG R. LAU, BARBARA A. MOSTELLA, \\ DAYNNA J. WOLFF, DAN M. RODEN, AND D. WOODROW BENSON \\ Department of Pediatrics, L.M. Bargeron Division of Pediatric Cardiology, University of Alabama at \\ Birmingham, Birmingham, Alabama, U.S.A. [W.H.J., Y.R.L., B.A.M.]; Division of Clinical Pharmacology, \\ Vanderbilt University, Nashville, Tennessee, U.S.A. [P.Y., T.Y., D.M.R.]; Medical University of South \\ Carolina, Charleston, South Carolina, U.S.A. [D.J.W., D.W.B.]
}

\begin{abstract}
Previous studies have identified mutations in five ion channel genes as a cause of long QT syndrome, a heterogeneous disorder characterized by prolongation of the QT interval, multiform ventricular tachycardia (torsades de pointes), seizures, syncope, and sudden death. However, in these studies, the average age of initial symptoms is in the third decade of life or later, and few reports have described the genetic causes of long QT syndrome presenting in the prenatal or neonatal period. We used a candidate gene approach to identify the genetic cause of long QT syndrome in an infant whose initial manifestations were detected in utero. Direct bidirectional sequencing of long QT syndrome genes identified a previously unreported HERG missense mutation (R752Q). Three asymptomatic family members were heterozygous for R752Q, and the proband, who manifested ventricular tachycardia in utero, was homozygous. R752Q was not found in 100 normal unrelated chromosomes. Paternal DNA was
\end{abstract}

ABSTRACT

unavailable for testing. Transient transfection of HERG generated robust $\mathrm{I}_{\mathrm{Kr}}$, but no current was observed for the mutant HERG. The HERG mutant, R752Q, is associated with a mild phenotype, inasmuch as family members with a heterozygous mutation appear unaffected. The homozygous mutation results in absence of functional $\mathrm{I}_{\mathrm{Kr}}$, causing a profound loss of HERG channel function, creating the equivalent of a "HERG knockout" and leading to a severe phenotype. (Pediatr Res 53: 744-748, 2003)
$\mathbf{Q T}_{\mathbf{c}}$, corrected QT interval
HERG, KVLQT1, KCNE1, and KCNE2, cardiac potassium channel component genes
$\mathbf{I}_{\mathbf{K r}}$, inward potassium rectifier current
LQTS, long QT syndrome

LQTS is a heterogeneous disorder characterized by prolongation of the QT interval, multiform ventricular tachycardia (torsades de pointes), seizures, syncope, and sudden death. Heterozygous missense mutations in the HERG gene, which encodes the $\alpha$ subunit of a potassium channel that induces the rapid component of the delayed rectifier current, $\mathrm{I}_{\mathrm{Kr}}$, are a common cause of LQTS (1). However, LQTS in the fetus or neonate are not reported in such studies; the initial symptoms in individuals with heterozygous HERG mutations are typically identified in older individuals, on average, in the third

Received June 25, 2002; accepted October 21, 2002.

Correspondence: Walter H. Johnson, Jr, M.D., H320, 620 South 20th St., Birmingham, AL 35294, U.S.A.; e-mail wjohnson@uab.edu

Supported, in part, by Grants HL49989 (D.M.R.) and HL04300 (D.W.B) from the National Institutes of Health, Bethesda, MD, U.S.A.

Current address for D.W.B.: Children's Hospital Medical Center, 3333 Burnet Ave., Cincinnati, OH, 45229, U.S.A.

DOI: 10.1203/01.PDR.0000059750.17002.B6 decade of life or later (1). We used a candidate gene approach to identify the genetic cause of LQTS in an infant whose initial manifestations were detected in utero. A previously unreported HERG mutation was identified. Family members with a heterozygous mutation had mild or absent phenotype, but the homozygous mutation resulted in a severe phenotype in the proband.

\section{METHODS}

Clinical characteristics. The proband was referred at $38 \mathrm{wk}$ gestational age for evaluation of irregular fetal heart rhythm. Echocardiographic study revealed normal cardiac structure and function. There was no atrioventricular valve regurgitation or signs of hydrops fetalis. Sinus rhythm with 1:1 atrioventricular conduction (120 beats per minute) was the predominant rhythm, but episodes of irregular fetal tachycardia (240-250 beats per minute) were observed. Simultaneous color Doppler- 
enhanced M-mode recordings of the fetal atrial and ventricular contractions and great vessel ejection revealed tachycardia with atrioventricular dissociation, consistent with nonsustained ventricular tachycardia.

After uneventful delivery, with birth weight of $2.9 \mathrm{~kg}$, surface ECG showed intermittent second-degree atrioventricular block, sinus rhythm with a prolonged $\mathrm{QT}_{\mathrm{c}}$ of $0.53 \mathrm{~s}$, and intermittent torsades de pointes (Fig. 1); there was no evidence of hearing loss. In the absence of a family history for deafness, syncope, sudden death (infant or adult), drowning, or seizures, ECG from five family members with $\mathrm{QT}_{\mathrm{c}}<450 \mathrm{~ms}$ were considered normal (Fig. 2). The father is thought to be living, but physical examination, ECG, and medical history could not be obtained.

Molecular genetic methods. Written informed consent was obtained from all participants in accordance with the Medical University of South Carolina Institutional Review Board for Human Research. A complete family medical history was obtained. An ECG was obtained and $10 \mathrm{~mL}$ of whole blood was collected from participating family members. Genomic DNA was extracted as previously described (2). To identify the molecular genetic basis of long QT syndrome, HERG, KVLQT1, KCNE1, and KCNE2 were used as candidate genes. The coding regions, including exon/intron boundaries, were amplified from genomic DNA as previously described (1). Bidirectional sequencing was performed using an automated cycle sequencer (ABI Prism 377 Sequencer, ABI BigDye Terminator Cycle Sequencing Kit, Applied Biosystems, Foster City, CA, U.S.A.). Sequence alterations were examined in the context of the open reading frame to determine whether there was corresponding change in the coding sense. Sequence alterations were confirmed by restriction enzyme digest or allele-specific oligonucleotide hybridization (2).

To exclude the possibility of a chromosome deletion of the HERG gene, three P1 clones containing the HERG gene were isolated from a human genomic library (3) and used to perform fluorescence in situ hybridization (FISH). Digoxigenin-11dUTP was incorporated into $1 \mu \mathrm{g}$ of DNA from each P1 clone via nick translation (Roche Molecular Biochemicals, Mannheim, Germany), and the labeled probes were hybridized to metaphase cells from the proband as previously described (4).
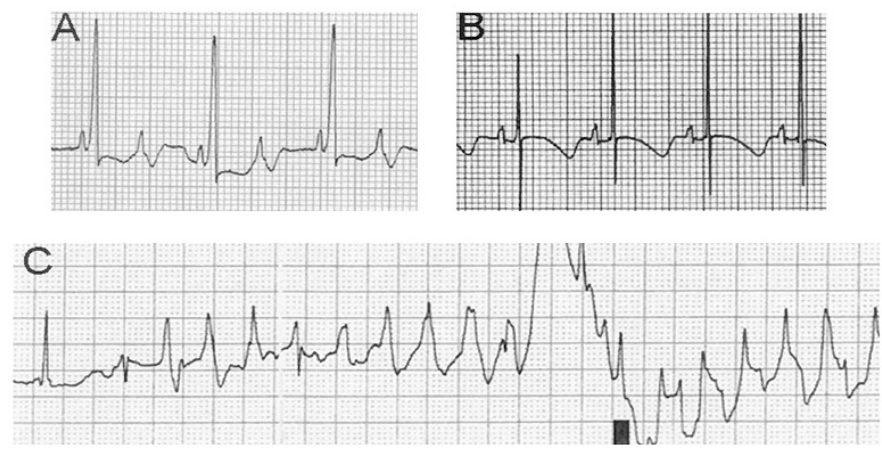

Figure 1. Proband electrocardiograms. During first few days of life, the proband demonstrated several electrocardiographic abnormalities, including second-degree atrioventricular block $(A)$, prolonged QT $\left(\mathrm{QT}_{\mathrm{c}}=0.53 \mathrm{~s}\right)(B)$, and torsades de pointes $(C)$.
The proband and three other family members (I-1, II-1, and II-3) were genotyped with polymorphic markers to exclude the possibility of maternal isodisomy of chromosome 7. Using previously described techniques, 14 short tandem repeat markers, including five markers from chromosome $7 \mathrm{q} 34-36$ where HERG is encoded, were used to genotype participants (5).

Biophysical characterization of HERG mutant. Chinese hamster ovary $(\mathrm{CHO})$ cells were transiently transfected with wild-type HERG or HERG mutant (R752Q) cDNA. Cells were cultured in DMEM medium supplemented with $10 \%$ horse serum at $37^{\circ} \mathrm{C}$, and transfected with lipofectamine according to the manufacturer's instructions (Invitrogen, Carlsbad, CA, U.S.A.). A plasmid encoding Green Fluorescent Protein (GFP) was cotransfected to assess transfection efficiency and to identify transfected cells for voltage-clamp analysis. The transfection mixture included $2 \mu \mathrm{g}$ of HERG isoforms (in pSI), $1 \mu \mathrm{g}$ of $\mathrm{GFP} / \mathrm{pRC}_{\mathrm{CMV}}$, and $12 \mu \mathrm{L}$ of lipofectamine reagent in 0.5 $\mathrm{mL}$ serum free DMEM for 6-8 $\mathrm{h}$, after which the standard medium was restored for $48 \mathrm{~h}$.

Cells were briefly trypsinized before electrophysiologic study at room temperature $\left(22-23^{\circ} \mathrm{C}\right)$. To obtain currentvoltage relations for HERG current, cells were held at -80 $\mathrm{mV}$, activating currents were elicited with depolarizing pulses from -70 to $+60 \mathrm{mV}$ in $10-\mathrm{mV}$ steps, and deactivating tail currents were recorded upon repolarization to $-40 \mathrm{mV}$. Pulses were delivered every $15 \mathrm{~s}$. The voltage at which half the channels are activated $\left(\mathrm{V}_{1 / 2}\right)$ was obtained by fitting tail current amplitudes as a function of voltage to the Boltzmann equation:

$$
y=\left[\left\{\left(A_{1}-A_{2}\right) /\left(1+e^{\left(\mathrm{X}-\mathrm{X}_{0}\right) / \mathrm{dx}}\right)\right\}+A_{2}\right] .
$$

Cell surface was obtained by integrating capacitative current recorded with brief steps to $-90 \mathrm{mV}$, and tail current magnitudes were normalized to cell surface as $\mathrm{pA} / \mathrm{pF}$. Values were expressed as mean \pm SEM.

Solutions. The intracellular pipette filling solution contained $110 \mathrm{mM} \mathrm{KCl}, 5 \mathrm{mM} \mathrm{K}{ }_{4}$ BAPTA, $5 \mathrm{mM} \mathrm{K}_{2} \mathrm{ATP}, 1 \mathrm{mM} \mathrm{MgCl}_{2}$, and $10 \mathrm{mM}$ HEPES. The solution was adjusted to $\mathrm{pH} 7.2$ with $\mathrm{KOH}$, yielding a final intracellular $\mathrm{K}^{+}$concentration of approximately $145 \mathrm{mM}$. The extracellular solution was Tyrode's containing $130 \mathrm{mM} \mathrm{NaCl}, 4 \mathrm{mM} \mathrm{KCl}, 1.8 \mathrm{mM} \mathrm{CaCl}_{2}, 1 \mathrm{mM}$ $\mathrm{MgCl}_{2}, 10 \mathrm{mM}$ HEPES, and $10 \mathrm{mM}$ glucose, and was adjusted to $\mathrm{pH} 7.35$ with $\mathrm{NaOH}(6)$.

\section{RESULTS}

Clinical course of proband. In response to torsade de pointes recurrence, second-degree heart block occurrence, and ventricular function deterioration, a variety of interventions were performed. On a regimen of temporary, transvenous right ventricular pacing, magnesium, lidocaine, and propranolol, ventricular systolic function improved. A dual-chamber permanent pulse generator (Medtronic Thera DR \#7968, Medtronic, Inc., Minneapolis, MN, U.S.A.) and epicardial pacing electrodes were implanted on d 5 of life. Left stellate ganglionectomy and potassium supplementation were added to the regimen after torsade de pointes recurrence. No subsequent ventricular tachycardia or bradycardia has been documented during $24 \mathrm{mo}$ of follow-up. Except for a Horner syndrome related to stellate gan- 


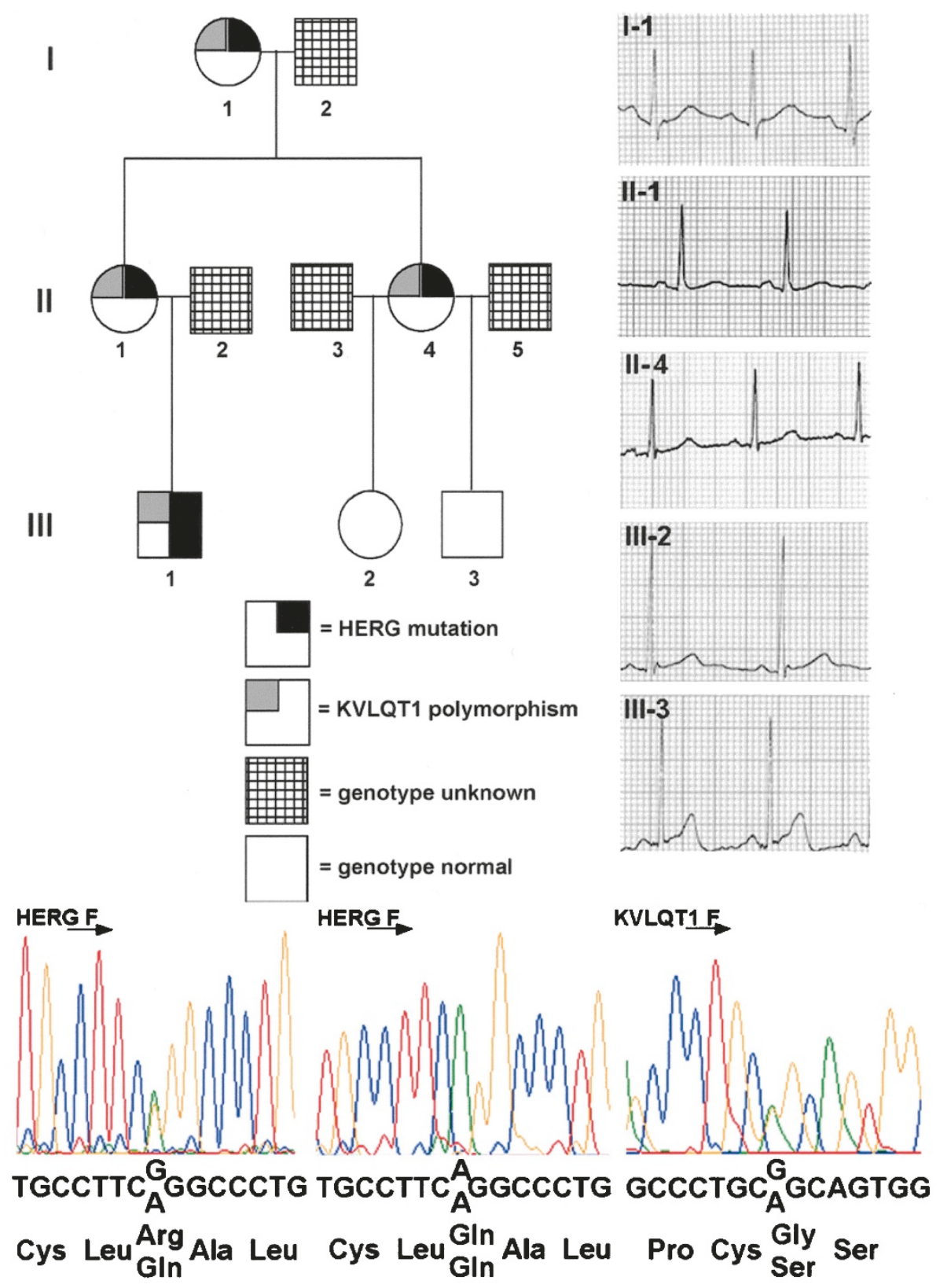

Figure 2. Pedigree, ECG, and DNA sequencing. The proband was a member of a three-generation African American kindred (top left). The QT interval was prolonged in proband (Fig. 1B) but normal in other family members (top right). Partial sequence of HERG and KVLQT1 (lower panel) illustrates the G2255A and G1927A transitions of HERG and KVLQT1, respectively. The HERG mutation changes the coding sense of codon 752 from arginine to glutamine; the proband is homozygous for glutamine at codon 752. The KVLQT1 sequence change is a previously reported polymorphism (8).

glionectomy, there were no neurologic abnormalities in the proband and neurodevelopment has been normal.

Molecular genetic results. A systematic survey of all coding regions of HERG, KVLQT1, KCNE1, and KCNE2 was performed using bidirectional sequencing. A $\mathrm{G}$ to $\mathrm{A}$ transition (G2255A) that changed the coding sense from arginine to glutamine (R752Q) was identified in HERG. Three asymptomatic family members (I-1, II-1, and II-4) were heterozygous for R752Q and the proband (III-1) was homozygous (Fig. 2). Allele-specific oligonucleotide hybridization (ASO) was used to confirm R752Q and exclude its presence in 100 normal unrelated chromosomes (7). A previously identified KVLQT1 polymorphism (G643S) was identified in four family members
(Fig. 2) (8). Paternal DNA was unavailable for testing, and other family members have declined evaluation.

Fluorescence in-situ hybridization (FISH) revealed signals on both chromosome 7 homologs with no evidence of HERG deletion in the proband (not shown). Maternal isodisomy was excluded because the inheritance pattern at 11 chromosome 7 short tandem repeat polymorphic markers was consistent with biparental inheritance. These findings, taken together with homozygosity of three chromosome $7 \mathrm{q} 35$ markers, suggest recessive inheritance of the mutant HERG allele.

Biophysical characterization of HERG (R752Q). Wild-type HERG generated robust $\mathrm{I}_{\mathrm{Kr}}$, but no current was observed with the mutant HERG (R752Q; two independent clones) (Fig. 3). 


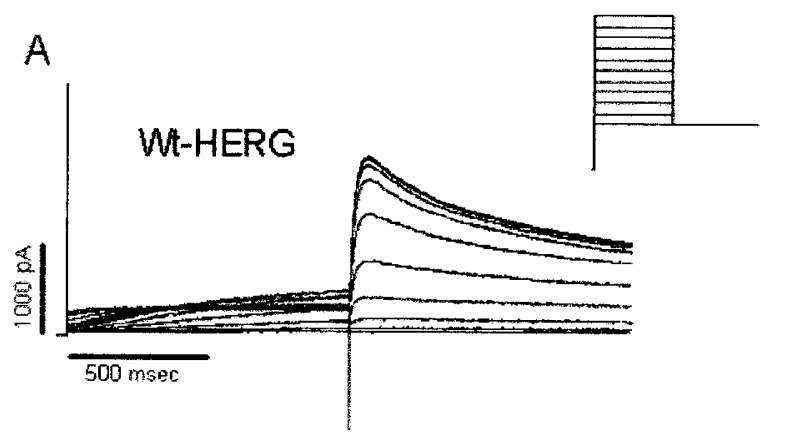

B
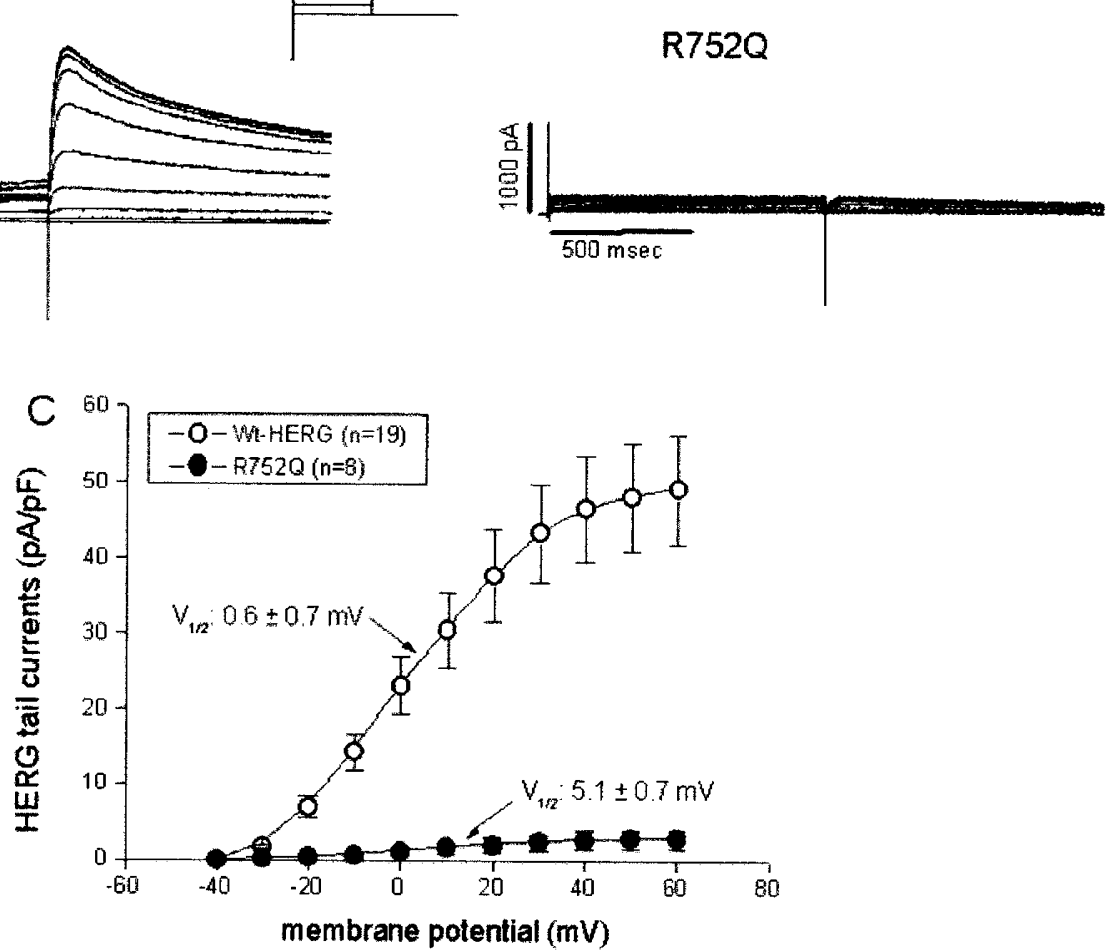

Figure 3. Biophysical characteristics of HERG R752Q. (A) Wild-type HERG current, recorded as described in the text. $(B)$ HERG-R752Q current. Note that there is only a very small activating current, with $\mathrm{I}_{\mathrm{Kr}}$-like deactivating tail current. (C) Current-voltage relationship for wild-type and $\mathrm{R} 752 \mathrm{Q}$ tail currents.

\section{DISCUSSION}

A HERG missense mutation, R752Q, results in absence of $\mathrm{I}_{\mathrm{Kr}}$. In the homozygous state, the loss of functional $\mathrm{I}_{\mathrm{Kr}}$ creates the equivalent of a "HERG knockout" and leads to a severe phenotype initially manifest in utero. Intrauterine LQTS manifestations have been previously described (9-11), but to our knowledge, the present report is the first example of intrauterine manifestations with subsequent genotype documentation. The heterozygous mutation is associated with a mild phenotype in this kindred, inasmuch as family members had neither symptoms nor electrocardiographic abnormalities. The reasons for the absent phenotype in this instance are currently unknown, but the association of LQTS gene mutations and reduced penetrance has been well described (12).

Homozygous HERG mutations have been reported twice previously and in both cases were associated with severe LQTS in infants $(13,14)$. L552S, also a HERG missense mutation, exhibited decreased channel activity at the end of the action potential; the severe phenotype of the homozygotes was thought to result from increased susceptibility to early after depolarizations (13). Homozygosity for an insertion mutation predicted to result in premature truncation of the HERG protein would be expected to result in complete absence of $\mathrm{I}_{\mathrm{Kr}}$, an effect similar to that observed in the proband we describe (14).

Another HERG mutation in codon 752, R752W, has been reported to abrogate $\mathrm{I}_{\mathrm{Kr}}$ because the channels do not reach the cell surface (15). R752Q may result in loss of HERG channel function because of a similar mechanism, or to abnormal gating. In either case, as shown in the present report, homozygosity of $\mathrm{R} 752 \mathrm{Q}$ results in near-total loss of channel function, i.e. absence of $\mathrm{I}_{\mathrm{Kr}}$.

The prevalence of ion channel sequence variants linked to arrhythmia risk in the general population may be relatively common (16). By themselves, such variants may either confer no abnormal phenotype, or a mild phenotype in heterozygous individuals, but manifest with a severe phenotype in homozygotes or compound heterozygotes. Thus, careful family history and directed molecular genetic testing (although not yet clinically available) may become advisable when evaluating a newly diagnosed child with a severe arrhythmia phenotype. This may have implications for family members with a mild phenotype as their risk during treatment with certain drugs may be increased (17), and their identification may allow avoidance of potentially adverse medication outcomes.

\section{REFERENCES}

1. Splawski I, Shen J, Timothy KW, Lehmann MH, Prori S, Robinson JL, Moss AJ, Schwartz PJ, Towbin JA, Vincent GM, Keating MT 2000 Spectrum of mutations in long-QT syndrome genes. KVLQT1, HERG, SCN5A, KCNE1, and KCNE2. Circulation 102:1178-1185

2. Benson DW, Silberbach GM, Kavanaugh-McHugh A, Cottrill C, Zhang Y, Riggs S, Smalls O, Johnson MC, Watson MS, Seidman JG, Seidman CE, Plowden J, Kugler JD 1999 Mutations in the cardiac transcription factor NKX2.5 affect diverse cardiac developmental pathways. J Clin Invest 104:1567-1573

3. Basson CT, Bachinsky DR, Lin RC, Levi T, Elkins JA, Soults J, Grayzel D, Kroumpouzou E, Traill TA, Leblanc-Straceski J, Renault B, Kucherlapati R, Seidman JG, Seidman CE 1997 Mutations in human TBX5 cause limb and cardiac malformation in Holt-Oram syndrome. Nat Genet 15:30-35 
4. Wolff DJ, Brown CJ, Schwartz S, Duncan AM, Surti U, Willard HF 1994 Small marker chromosomes lack the $\mathrm{X}$ inactivation center: implications for karyotype/ phenotype correlations. Am J Hum Genet 55:87-95

5. Benson DW, Sharkey A, Fatkin D, Lang P, Basson CT, McDonough B, Strauss AW, Seidman JG, Seidman CE 1998 Reduced penetrance, variable expressivity and genetic heterogeneity of familial atrial septal defect. Circulation 97:2043-2048

6. Yang T, Snyders DJ, Roden DM 2001 Drug block of IKr: model systems and relevance to human arrhythmias. J Cardiovasc Pharmacol 38:737-744

7. Benson DW, MacRae CA, Vesely MR, Walsh EP, Seidman JG, Seidman CE, Satler CA 1996 Missense mutation in the pore region of HERG causes familial long QT syndrome. Circulation 93:1791-1795

8. Itoh T, Tanaka T, Nagai R, Kikuchi K, Ogawa S, Okada S, Yamagata S, Yano K, Yazaki Y, Nakamura Y 1998 Genomic organization and mutational analysis of KVLQT1, a gene responsible for familial long QT syndrome. Hum Genet 103:290-294

9. Hofbeck M, Ulmer H, Beinder E, Sieber E, Singer H 1997 Prenatal findings in patients with prolonged QT interval in the neonatal period. Heart 77:198-204

10. Yamada M, Nakazawa M, Momma K 1998 Fetal ventricular tachycardia in long QT syndrome. Cardiol Young 8:119-122

11. Ohkuchi A, Shiraishi H, Minakami H, Eguchi Y, Izumi A, Sato I 1999 Fetus with long QT syndrome manifested by tachyarrhythmia: a case report. Prenat Diagn 19:990-992
12. Priori SG, Napolitano C, Schwartz PJ 1999 Low penetrance in the long-QT syndrome. Circulation 99:529-533

13. Piippo K, Laitinen P, Swan H, Toivonen L, Viitasalo M, Pasternack M, Paavonen K, Chapman H, Wann KT, Hirvela E, Sajantila A, Kontula K 2000 Homozygosity for a HERG potassium channel mutation causes a severe form of long QT syndrome: identification of an apparent founder mutation in the Finns. J Am Coll Cardiol 35:1919-1925

14. Hoorntje T, Alders M, van Tintelen P, van der Lip K, Sreeram N, van der Wal A, Mannens M, Wilde A 1999 Homozygous premature truncation of the HERG protein: the human HERG knockout. Circulation 100:1264-1267

15. Ficker E, Thomas D, Viswanathan PC, Dennis AT, Priori SG, Napolitano C, Memmi M, Wible BA, Kaufman ES, Iyengar S, Schwartz PJ, Rudy Y, Brown AM 2000 Nove characteristics of a misprocessed mutant HERG channel linked to hereditary long QT syndrome. Am J Physiol 279:H1748-H1756

16. Splawski I, Timothy KW, Tateyama M, Clancy CE, Malhotra A, Beggs AH, Cappuccio FP, Sagnella GA, Kass RS, Keating MT 2002 Variant of SCN5A sodium channel implicated in risk of cardiac arrhythmia Science 297:1333-1336

17. Yang P, Kanki H, Drolet B, Yang T, Wei J, Viswanathan PC, Hohnloser SH, Shimizu W, Schwartz PJ, Stanton M, Murray KT, Norris K, George Jr AL, Roden DM 2002 Allelic variants in long-QT disease genes in patients with drug-associated torsades de pointes. Circulation 105:1943-1948 